Original Contribution

\title{
SERUM LEVELS OF TNF-A AND SPIROMETRIC PARAMETERS IN WORKERS EXPOSED TO INORGANIC DUST
}

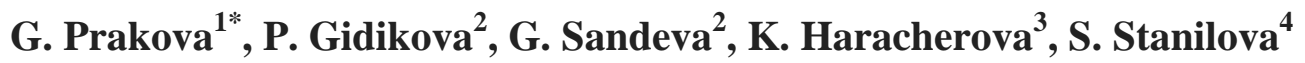 \\ ${ }^{1}$ First Department of Internal Medicine, Medical Faculty, Trakia University, Stara Zagora, Bulgaria \\ ${ }^{2}$ Department of Hygiene, Infectious Diseases and Epidemiology, Medical Faculty, Trakia University, \\ Stara Zagora, Bulgaria \\ ${ }^{3}$ Occupational Medical Service "Zagora Medical”, Stara Zagora, Bulgaria \\ ${ }^{4}$ Department of Molecular Biology and Immunology, Medical Faculty, Trakia University, \\ Stara Zagora, Bulgaria
}

\begin{abstract}
Inhalation of inorganic particles results in activation of the alveolar macrophages with subsequent release of inflammatory cytokines and fibroblast proliferation. PURPOSE of this work was to analyze the serum levels of TNF- $\alpha$ and basic spirometric parameters in clinically healthy workers exposed to inorganic dust of different chemical composition. METHODS: the studied workers were divided into two groups depending on the characteristics of the dust: Group A (29 workers) exposed to dust from moulding mass for metal castings (quartz sand with added coal ash and bentonite) and Group B (31 workers) exposed to mixed dust composed mainly of iron and artificial abrasives. Determination of serum TNF- $\alpha$ was performed by ELISA kit, and the spirometric study with a portable spirometer. RESULTS: We found significant higher levels of TNF- $\alpha$ in workers from Group A $(16,01 \pm 2,86 \mathrm{pg} / \mathrm{ml})$ compared to those Group B $(14,49 \pm 2,03 \mathrm{pg} / \mathrm{ml}), \mathrm{p}<0.02$, and to the control group $(13,94 \pm 2,23 \mathrm{pg} / \mathrm{ml})$, $\mathrm{p}<0.001$. There were no significant differences in FVC, FEV1, FEV1/FVC, PEF between the two groups of workers exposed to dust. CONCLUSIONS: The chemical composition of inorganic aerosols affects the amount of released TNF- $\alpha_{2}$ which is an early biomarker for assessing exposure to free crystalline silica.
\end{abstract}

Key words: inorganic dust, TNF- $\alpha$, spirometry

\section{INTRODUCTION}

Pneumoconioses and occupational interstitial lung disease (OILD) are a clinically heterogeneous group of diseases whose etiological causes are being constantly explored due to the wide industrial use of innovative materials. The clinical course of pneumoconioses does not differ from that of non-professional kinds, which defines the major importance of early diagnosis for the introduction of primary and secondary prevention (1). Measurement of soluble cytokines in vivo and in vitro is becoming increasingly important in studying and controlling pulmonary diseases $(2,3)$. The discovered link between changes in cytokine levels and the emergence and development of various functional symptoms is a reason many authors recommend cytokines as new

\footnotetext{
*Correspondence to: prof. Dr G. Prakova, MD, PhD, Ist Department of Internal Medicine, Medical Faculty, Trakia University, 11 Armeyska Str, 6000 Stara Zagora, Bulgaria, Email: prakova@hotmail.com
}

biomarkers in preclinical, clinical and epidemiological studies, and especially in risk assessment (4-9).

The use of the term "biomarker" dates back to 1980 (10). In 1998, a working group at the National Health Institute in Bethesda, Maryland, USA defines a biomarker as "a parameter that can be measured objectively and evaluated as an indicator of normal biological response, pathogenic process or drug response to therapeutic intervention". Biomarkers are measurable biological parameters that change in response to exposure to xenobiotics, environmental or physiological stressors, and serve as indicators of toxic and other external influences. Biomarkers show the change in expression or state of a protein, which correlates to risk or to disease progression, as well as to the susceptibility to a particular treatment $(11,12)$.

Immune cells interact with each other by releasing chemical substances called cytokines 
that affect other cells and coordinate appropriate immune responses. Cytokines include interleukins, interferons, growth factors, monokines, and lymphokines (13). It was found that pro-inflammatory cytokines (IL-1 and TNF- $\alpha$ ) trigger a systemic inflammation and could worsen disease by inducing fever, inflammation, tissue destruction, etc. (14-16).

Purpose of the present study was to analyze levels of serum TNF- $\alpha$ and some spirometric parameters in healthy workers exposed to inorganic dust of different composition in the work environment.

\section{MATERIALS AND METHODS}

The study included 60 clinically healthy workers exposed to inorganic dust ( 38 men and 22 women) and 38 healthy controls (12 men and 26 women). Depending on dust composition the tested workers were divided into two groups. The first group (Group A) comprised of 29 workers (27 men and 2 women), exposed to dust from moulding mass for metal castings (quartz sand with added coal ash and bentonite). This dust contained three main ingredients: $98 \%$ dried quartz sand (respirable free crystalline silica below 2\%); bentonite (containing bentonite clay $85 \%$, quartz $2 \%$, cristobalite up to $1 \%$, tridymite up to $1 \%$ ) and carboplast (composed mainly of coal dust and ashes). The mean age of Group A was 39 years with an average exposure time of eight years (from 0.5 to 30 years). The second group (Group B) included 31 workers (11 men and 20 women) exposed to a mixed dust
PRAKOVA G., et al. composed mainly of iron and artificial abrasives. The average age and exposure time of the Group B were 40 and 9 years (from 0.5 to 30 years) respectively. In both groups, smokers were more than non-smokers: 19 against 10 in Group A, and 16 against 15 in Group B. The average age of the control group was 45 years.

Serum samples from healthy workers and control group were extracted from venous blood at room temperature, and stored at $-70^{\circ} \mathrm{C}$ until evaluation. The quantity determination of TNF- $\alpha$ in sera was performed by ELISA kits (Invitrogene, Austria) following the manufacturer's protocol. Cytokine concentrations were determined by using standard curve constructed with kit's standards. The minimal detectable dose of the TNF- $\alpha$ ELISA kit was $0.7 \mathrm{pg} / \mathrm{ml}$.

Expiratory flow-volume loops were recorded according to the European Respiratory Society Guidelines on a Spirolab III (Italy). The forced expiratory volume in $1 \mathrm{sec}$ (FEV1) and forced vital capacity (FVC) were recorded and expressed as a percentage of the predicted reference value (17).

\section{RESULTS}

Serum levels of TNF- $\alpha$ in workers exposed to dust and in a control group are shown in Figure 1. We found significantly higher levels of TNF- $\alpha$ in the exposed group $(15,23 \pm 2,56$ $\mathrm{pg} / \mathrm{ml})$ compared to the control group $(13,94 \pm$ $2,23 \mathrm{pg} / \mathrm{ml}), \mathrm{p}<0.01$.

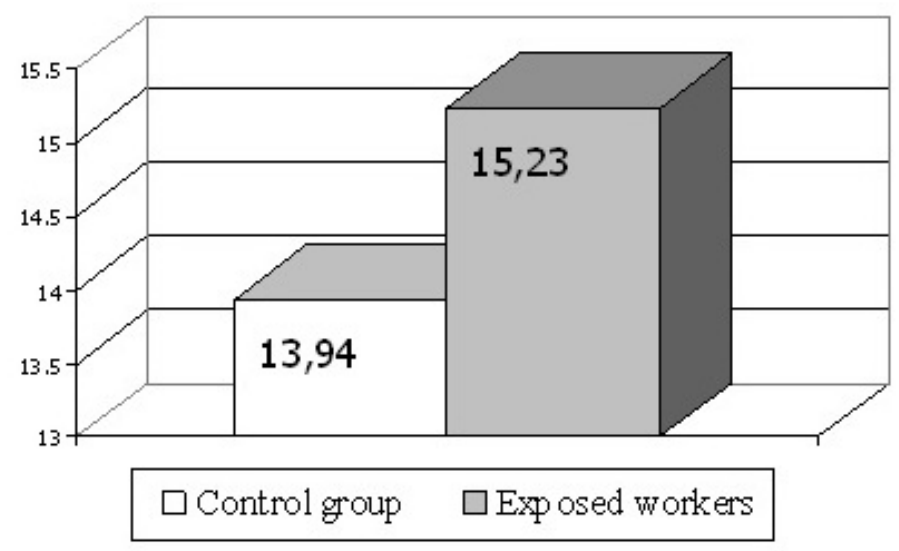

Figure 1. Serum levels of TNF- $\alpha(\mathrm{pg} / \mathrm{ml})$ in workers exposed to inorganic dust and in a control group.

Serum levels of TNF- $\alpha$ in workers exposed to dust with a different chemical composition and the control group are presented in Figure 2. Highest level of TNF- $\alpha$ were measured in workers exposed to the moulding dust (Group A) as compared to the control group, and compared to Group B. 


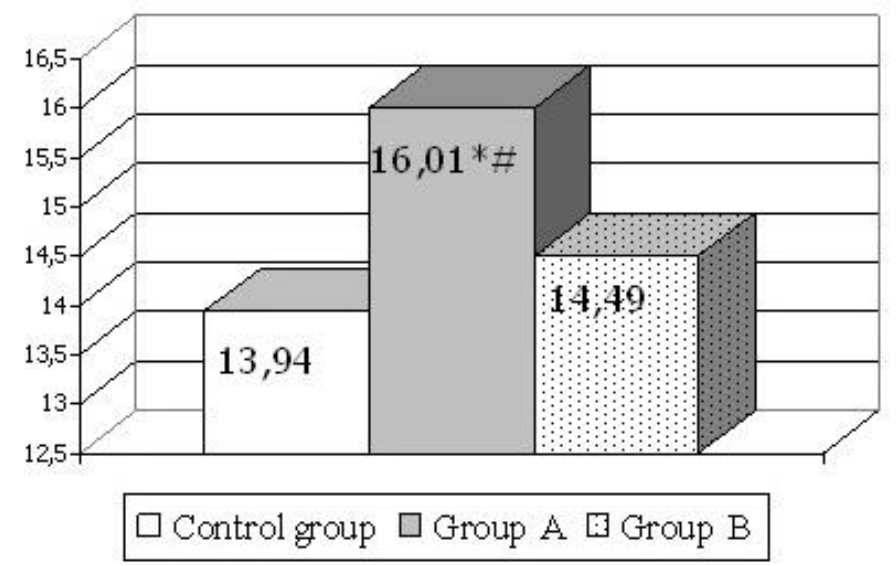

\section{* Statistically significant difference to the control group $(\mathrm{p}<0.001)$. \# Statistically significant difference to group B $(\mathrm{p}<0.02)$.}

Figure 2. Serum levels of TNF- $\alpha(\mathrm{pg} / \mathrm{ml})$ in workers exposed to different kinds of inorganic dust (Groups A and B) and in the control group.

Mean serum levels of TNF- $\alpha$ in the exposed workers divided by smoking status are shown in Table 1. There is a tendency for higher levels of TNF- $\alpha$ in smokers compared to nonsmokers in both treatment groups workers.

Table 1. Serum levels of TNF- $\alpha(\mathrm{pg} / \mathrm{ml})$ in workers exposed to inorganic dust divided by smoking status.

\begin{tabular}{|l|c|c|}
\hline \multicolumn{1}{|c|}{ Group } & Smokers TNF- $\alpha(\mathrm{pg} / \mathrm{ml})$ & Non-smokers TNF- $\alpha(\mathrm{pg} / \mathrm{ml})$ \\
\hline \multirow{2}{*}{ All Exposed } & $\mathbf{n = 3 5}$ & $\mathbf{n = 2 5}$ \\
& $15,66 \pm 2,88$ & $14,62 \pm 1,92$ \\
\hline \multirow{2}{*}{ Group A } & $\mathbf{n = 1 9}$ & $\mathbf{n = 1 0}$ \\
& $16,48 \pm 3,14$ & $15,12 \pm 2,06$ \\
\hline \multirow{2}{*}{ Group B } & $\mathbf{n}=\mathbf{1 6}$ & $\mathbf{n = 1 5}$ \\
& $14,69 \pm 2,25$ & $14,29 \pm 1,82$ \\
\hline
\end{tabular}

Table 2. Spirometric parameters in workers exposed to dust from group A and B.

\begin{tabular}{|l|c|c|}
\hline \multicolumn{1}{|c|}{ Group } & $\begin{array}{c}\text { Group A } \\
\text { Parameter }\end{array}$ & $\begin{array}{c}\text { Group B } \\
\mathbf{n = 2 7}\end{array}$ \\
\hline FEV1 $(\%)$ & $89,46 \pm 18,29$ & $91,00 \pm 16,75$ \\
\hline FVC $(\%)$ & $86,36 \pm 21,60$ & $87,26 \pm 17,34$ \\
\hline FEV1/FVC & $109,11 \pm 17,40$ & $109,33 \pm 12,19$ \\
\hline PEF $(\%)$ & $62,64 \pm 26,16$ & $64,78 \pm 19,97$ \\
\hline
\end{tabular}

No significant difference in the levels of the measured mean group spirometric parameters was detected in workers from the two groups.

\section{DISCUSSION}

TNF- $\alpha$, also known as cachectin, is a proinflammatory cytokine with a wide variety of functions (18-20). TNF- $\alpha$ is synthesized predominantly by immune cells such as activated macrophages, monocytes, and lymphocytes, and is important in early inflammation, in development and progression of several diseases, including pulmonary fibrosis (21). TNF- $\alpha$ is responsible for the onset and persistence of the inflammatory response observed in the lungs of patients with progressive massive fibrosis. TNF- $\alpha$ can directly induce the proliferation of fibroblasts as well as the production of other proinflammatory mediators (22). By stimulating 
secretion of interleukin- 6 , TNF- $\alpha$ can stimulate cell proliferation and induce cell differentiation under certain conditions (18-20).

The significantly higher levels of TNF- $\alpha$ in workers exposed to inorganic dust compared to the control group, identified in our study, confirm the stimulation of the immune system, where the activated cells produce proinflammatory cytokines, in this case TNF- $\alpha$. Similar results by E. Codorean et al., 2011, indicate significantly higher levels of TNF- $\alpha$ in workers exposed to coal dust compared to a control group, and increased levels of the cytokine proportional to the duration of exposure (23). According to J.S. Lee et al., 2010, considerable release of TNF- $\alpha$ in subjects with the stage 0/1 ILO compared to controls supports the hypothesis for the crucial role of TNF- $\alpha$ in the pathogenesis of coal pneumoconiosis (24). TNF- $\alpha$ has been reported as a biomarker for progressive pneumoconiosis with levels correlating to the severity of the disease $(25,26)$, i.e. TNF- $\alpha$ is a useful indicator of exposure to coal dus, as well as biomarker for pneumoconiosis with progressive lung fibrosis (27).

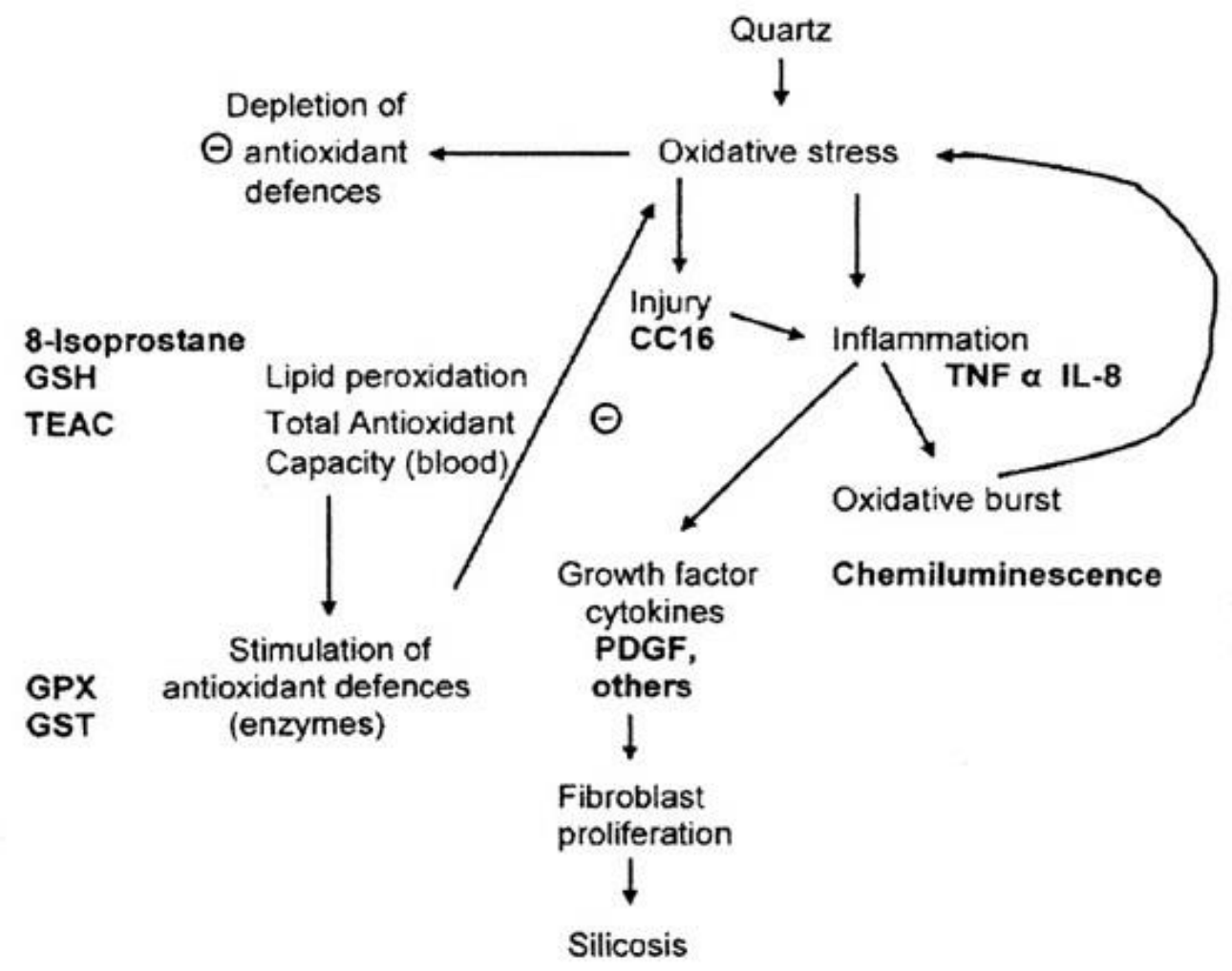

Figure 3. Schematic presentation of the mechanisms involved in crystalline silica-induced oxidative stress, injury, and fibrosis, with relevant useful biomarkers identified in these processes (M. Gulumian et al., 2006).

Well-known fact is that formation of collagen in the lungs depends on the nature and chemical composition of inhaled dust. Typical collagen fibroses are caused by silica, asbestos, coal dust, and non-collagen fibroses - by barite dust, iron, inert non-fibrogenic dusts (28). The pathogenic mechanism of silica is presented by direct activation of alveolar macrophages with subsequent production and secretion of inflammatory cytokines that induce fibroblast proliferation (29). Initial biological responses to $\mathrm{SiO}_{2}$ are associated with immune system stimulation, followed by the death of macrophages. Activated macrophages produce cytokines IL-1 and TNF and stimulate fibroblasts (30-32). The most common clinical type is chronic silicosis, which occurs after intense and prolonged exposures and a latent period of 10 to 40 years (33).

The measured significantly higher level of TNF- $\alpha$ in workers from Group A than those of Group B confirms the importance of dust composition to macrophageal activity and the secretion of cytokines. Workers exposed to dust from molding mixture, bentonite and carboplast (Group A) had significantly higher levels of the pro-inflammatory cytokine TNF- $\alpha$ compared to those of Group B, who were exposed to iron dust and synthetic abrasives, as well as compared to the control group. No significant difference in the level of TNF- $\alpha$ 
was demonstrated between the control group and Group B of exposed workers. These results substantiate the role of crystalline silica for cytokine release from the activated macrophages. The mediation of TNF- $\alpha$ in quartz induced pulmonary fibrosis is the basis of a proposed treatment with specific antiTNF- antibodies for prevention and reduction of fibrosis (34).

Comparing levels of TNF- $\alpha$ in smokers and non-smokers from the respective groups surveyed, the highest levels were found in smokers from Group A. These data correspond to those reported by F. Petrescu et al., 2010, who found that higher levels of TNF- $\alpha$ in healthy smokers than healthy non-smokers, which could be used as a biomarker for the risk of pulmonary diseases (35). Elevated levels of TNF- $\alpha$ in smokers compared to non-smokers in the two groups are probably in conjunction with the synergistic effect of dust particles and cigarette smoke and determines the increased risk of lung fibrosis when exposed to dust and cigarette smoke.

No significant difference was recorded in the mean values of the spirometric parameters in both exposed groups. There is a tendency for lower levels in exposed Group A compared to Group B for all spirometric parameters FEV1, FVC, FEV1/FVC and PEF. Relationship between airflow restriction and TNF- $\alpha$ is shown in a study of T.H. Jorna et al., 1994, which report an increased release of TNF- $\alpha$ in subjects with FEV $<80 \%$ (36). Similar results observed J.S. Lee et al., 2010: average values of TNF- $\alpha$ were significantly higher in subjects with FEV1 $<80 \%$ compared to those in FEV1> 80\% (23). The absence of significant differences in the spirometric parameters may be due to the fact that we studied clinically healthy people without registered respiratory diseases or functional deficits and abnormalities in spirometric testing.

The results of this study confirm the possibility that TNF- $\alpha$ can be used as an early biomarker for estimation of free crystalline silica exposure and effect, and as $\mathrm{s}$ forecast for the development of a fibrotic process in the lungs and onset of disease. Recording changes in this biomarker's levels in certain groups of workers could be used in planning and evaluation of measures to reduce dust exposure in various industries as well as to identify individuals at higher risk of developing silicosis.

\section{REFERENCES}

PRAKOVA G., et al.

1. Sartorelli, P. and Paolucci, V., Diagnostic criteria of pneumoconiosis. Prevent Res, 3(4):309-324, 2013.

2. De Jager, W., Velthuis, T.E., Prakken, B.J., Kuis, W. and Rijkers, G.T., Simultaneous Detection of 15 Human Cytokines in a Single Sample of Stimulated Peripheral Blood Mononuclear Cells, Clin Diagn Lab Immunol, 10(1):133-139, 2003.

3. Chowdhury, F., Williams, A. and Johnson, P., Validation and comparison of two multiplex technologies, Luminex and Mesoscale Discovery, for human cytokine profiling. J Immunol Methods, 340(1):5564, 2009.

4. Kennedy I.M., The health effects of combustion-generated aerosols. Proc Combust Inst, 31(2):2757-2770, 2007.

5. Codorean, E., Tanase, M., Albulesku, L., Popesku, I.D., Mihai, S., Murariu, A. and Tanase, C., Novel developmental immunotoxicology monitoring risk assessment for human populations from environmental pollution; alternative methods in vitro. In: Brebbia C.A. (ed), Environmental Health Risk V, WIT press, UK, pp 233-246, 2009.

6. Meghea, A., Murariu, A., Tanase C. and Codorean E., Heavy metals contamination of commercial fish foodstuff - potential health risks on human consumers. Environm Engin and Manag J, 8:233-236, 2009.

7. Wang, Z., Neuburg, D., Li, C., Su, L., Kim, J.Y., Chen, J.C. and Christiani, D.C., Global Gene Expression Profiling in Whole-Blood Samples from Individuals Exposed to Metal Fumes. Environ Health Perspect, 113(2):233-241, 2005.

8. Langezaal, I., Hoffmann, S., Hartung, T. and Coecke S., Evaluation and prevalidation of an immunotoxicity test based on human whole-blood cytokine release. Altern Lab Anim., 30(6):581-95, 2002.

9. Tarrant, J. M., Blood Cytokines as Biomarkers of In Vivo Toxicity in Preclinical Safety Assessment: Considerations for Their Use. Toxicol Sci, 117:4-16, 2010.

10.Aronson, J., Biomarkers and surrogate endpoints. Br J Clin Pharmacol, 59(5):491494, 2005.

11.Strimbu, K. and Tavel, J., What are Biomarkers. Curr Opin HIV AIDS, 5(6):463-466, 2010.

12.Atkinson, A.J., Colburn, W.A., DeGruttola, V.G, DeMets, D.L., Downing, G.J., Hoth, D.F., Oates, J.A., Peck, C.C., Schooley, 
PRAKOVA G., et al.

R.T., Spilker, B.A., Woodcock J. and Zeger, S.L., Biomarkers and surrogate endpoints: preferred definitions and conceptual framework. Clin Pharmacol Ther, 69(3):89-95, 2001.

13.Naumova, E., Altunkova, I., Clinical Immunology, Lice Publishings, Sofia, Bulgaria, 2008.

14.Dinarello, C.A., Proinflammatory cytokines. Chest, 118(2):503-508, 2000.

15.Cheung, C.Y., Poon, L.L., Lau, A.S., et al. Induction of proinflammatory cytokines in human macrophages by influenza A (H5N1) viruses: a mechanism for the unusual severity of human disease. Lancet, 360(9348): 1831-1837, 2002.

16.Strober, W. and Fuss, I.J., Proinflammatory cytokines in the pathogenesis of inflammatory bowel diseases. Gastroenterology, $\quad$ 140(6):1756-1767, 2011.

17.Miller, M.R., Hankinson, J., Brusasco, V., Burgos, F., Casaburi, R., Coates, A. and Crapo, R., Standardization of Spirometry, Eur Respir J, 26:319-338, 2005.

18. Mukhopadhyay, S., Hoidal, J.R. and Mukherjee, T.K., Role of TNF $\alpha$ in pulmonary pathophysiology. Respir Res, 7:125, 2006.

19.Beutler, B. and Cerami, A., The history, properties, and biological effects of cachectin. Biochemistry, 27(20):7575$7582,1988$.

20.Vilcek, J. and Lee, T.H., Tumor necrosis factor. New insights into the molecular mechanisms of its multiple actions. $J$ Biol Chem, 266(12):7313-7316, 1991.

21.Schins, R.P. and Borm, P.J., Mechanisms and mediators in coal dust induced toxicity: a review. Ann Occup Hyg, 43:7-33, 1999.

22.Vanhée, D., Gosset, P., Boitelle, A., Wallaert, B. and Tonnel, A.B., Cytokines and cytokine network in silicosis and coal workers' pneumoconiosis. Eur Respir J, 8:834-842, 1995.

23.Codorean, E., Raducanu, A., Albulesku, L., Tanase, C., Meghea, A. and Albulesku, R., Multiplex Cytokine Profiling in whole blood from individuals occupationally exposed to particulate coal species. Rom Biotechnol Lett, 16(6):6748-6759, 2011.

24.Lee, J.S., Shin, J.H., Lee, J.O., Lee, K.M., Kim, J.H. and Choi, B.S., Serum levels of interleukin-8 and tumor necrosis factoralpha in coal workers' pneumoconiosis: one-year follow-up study. Saf Health Work, 1(1):69-79, 2010.
25.Zhai, R., Liu, G., Ge, X., Bao, W., Wu, C., Yang, C. and Liang, D., Serum levels of tumor necrosis factor-alpha (TNF-alpha), interleukin 6 (IL-6), and their soluble receptors in coal workers' pneumoconiosis. Respir Med, 96(10):829, 2002.

26.Schins, R.P. and Borm, P.J., Epidemiological evaluation of release of monocyte TNF-alpha as an exposure and effect marker in pneumoconiosis: a five year follow up study of coal workers. Occup Environ Med, 52:441-450, 1995.

27.Gulumian, M., Borm, P.J., Vallyathan, V., Castranova, V., Donaldson, K., Nelson, G. and Murray, J., Mechanistically identified suitable biomarkers of exposure, effect, and susceptibility for silicosis and coal-worker's pneumoconiosis: a comprehensive review. $J$ Toxicol Environ Health B Crit Rev, 9:357395, 2006.

28.Savov, A., Occupational Diseases. MUSofia, Clinical Center for Occupational Diseases, Rahl Kolobar, Sofia, Bulgaria, 2003.

29.Castranova, V. and Vallyathan, V., Silicosis and coal workers' pneumoconiosis. Environ Health Perspect, 108(4):675-684, 2000.

30.Petrova, E., Role of occupational factors in the development of some autoimmune diseases. Bul Med J, 3(2):55-61, 2009.

31.Chen, M. and Von Mikecz, A., Xenobioticinduced recruitment of autoantigens to nuclear proteasomes suggests a role for altered antigen processing in scleroderma. Ann NY Acad Sci, 1051:382-389, 2005.

32.Pernis, B., Silica and the immune system. Acta Biomed, 76(2):38-44, 2005.

33.De Vuyst, P. and Camus, P., The past and present of pneumoconioses. Curr Opin Pulm Med, 6:151-156, 2000.

34.Piguet, P.F. and Vesin, C., Treatment by human recombinant soluble TNF receptor of pulmonary fibrosis induced by bleomycin or silica in mice. Eur Respir $J$, 7:515-518, 1994.

35.Petrescu, F., Voican, S.C. and Silosi, I., Tumor necrosis factor- $\alpha$ serum levels in healthy smokers and nonsmokers. Int $J$ Chron Obstruct Pulmon Dis, 5:217-222, 2010.

36.Jorna, T.H., Schins, R.P., Lenaerts, L., Derhaag, T.J., Wouters, E.F. and Borm, P.J., Airflow obstruction and monocyte TNF-release in coal workers. Exp Lung Res, 20(5):421-431, 1994. 